\title{
Effects of Seasonal Allergic Rhinitis on Driving Ability, Memory Functioning, Sustained Attention, and Quality of Life ${ }^{\S}$
}

\author{
Monique A.J. Mets ${ }^{1}$, Edmund R. Volkerts ${ }^{1}$, Erwin A. Dunnebier ${ }^{2}$, Lieke M. de Senerpont Domis ${ }^{1}$, \\ Berend Olivier $^{1}$ and Joris C. Verster ${ }^{*}, 1$ \\ ${ }^{1}$ Utrecht Institute for Pharmaceutical Sciences, Department of Psychopharmacology, Utrecht University, P.O. Box \\ 80082, 3508 TB, Utrecht, the Netherlands \\ ${ }^{2}$ Utrecht Medical Center, Department of Otorhinolaryngology, PoBox 85500, 3508 GA, Utrecht, The Netherlands
}

\begin{abstract}
Background: Seasonal allergic rhinitis (SAR) has shown to affect quality of life and impair cognitive functioning.

Objective: The objective of this study was to compare driving ability, memory, and psychomotor performance during grass pollen season with winter season in untreated patients with SAR.

Methods: Patients with SAR were trained and tested during the grass pollen season (summer) and winter. An on-the-road driving test during normal traffic conditions was performed. Primary parameter is the Standard Deviation of Lateral Position (SDLP), i.e. the weaving of the car. In addition, a word learning test and continuous performance test were performed and quality of life was assessed. Patients were included if in winter the Total 5-Symptoms Score (T5SS) was $<3$ and in summer the T5SS was $>3$.

Results: 70 patients were recruited of which 22 started the study. Fifteen patients completed the study of which 11 met the inclusion criteria. These 11 patients had a mean T5SS of 6.8 in summer and 0.6 in winter. Patient reported a significantly reduced overall quality of life during grass pollen season $(\mathrm{p}<0.0001)$. No significant effects were found on the driving test, except a significant (but not relevant) decrease in mean speed during the grass pollen season $(\mathrm{p}<0.035)$. No significant effects were found on the word learning test and continuous performance test.
\end{abstract}

Conclusion: Our data suggest that moderate SAR symptoms do not impair driving ability, memory functioning and continuous performance. However, given the small sample size future studies should confirm these findings.

\section{INTRODUCTION}

About 20 to $40 \%$ of US population suffers from seasonal allergic rhinitis (SAR) [1-3]. Among them are approximately 12 to 15 million workers [1]. In the USA, SAR causes an estimated 37 million dollar of lost work days [2,3] and significantly costs associated with reduced work performance [4].

Sedation is associated with reduced work performance or absenteeism when suffering from SAR. Sedation may be a direct result of histamine overload during allergic reactions in patients suffering from seasonal or perennial rhinitis. Sedation caused by SAR may result in impaired cognitive and psychomotor functioning [5], decreased productivity [6], impaired learning $[7,8]$, poorer psychological functioning [9] and reduced quality of life [10-12]. Thus, SAR itself has shown to interfere with daily activities.

Antihistamine drugs $\left(\mathrm{H}_{1}\right.$ receptor antagonists $)$ were developed to reduce SAR symptoms. Antihistamine drugs of

*Address correspondence to this author at the Utrecht Institute for Pharmaceutical Sciences, Department of Psychopharmacology, Utrecht University, PO BOX 80082, 3508 TB, Utrecht, the Netherlands; Tel: +31 30253 6909; Fax: +31 30253 7900; E-mail: j.c.verster@uu.nl

${ }^{\S}$ The study is registered at www.clinicaltrials.gov (identifier NCT00223587) the first and second generation administered to healthy volunteers have shown to impair cognitive performance and behavioral skills and abilities, including driving a car [13]. In patients, antihistamines have shown to affect performance negatively [14], whereas others report performance improvement [15]. It is likely that in patients the impairing effects of antihistamine drugs must be added to the impairing effects of SAR itself. On the other hand, relief of SAR symptoms may improve performance. Studies conducted in healthy volunteers may therefore give a too positive view of real life effects of antihistamine treatment on driving ability in patients with SAR. In this context, the present study was designed to examine on-the-road driving performance in patients with untreated SAR to establish whether driving during the grass pollen season differs from driving performance during winter (non-grass pollen season). In addition, it will be examined whether SAR affects memory functioning since this area has not been examined thoroughly by previous research. Performance on a vigilance task was included to gain supportive evidence for the driving test results.

\section{METHODS}

\section{Patients}

Twenty-four outpatients (men and women, aged 21 to 50 years old) suffering from SAR and in possession of a valid drivers license were scheduled to participate in the study. They 
should have had a history of SAR to prevalent pollen aeroallergens such as grass and/or weed pollen for at least 2 years prior to randomization confirmed by a positive skin test (wheal $\geq 3 \mathrm{~mm}$ larger than the diluent control for prick testing or positive RAST ( $\geq$ Class 3 or $\geq 3.5 \mathrm{UI} / \mathrm{mL}$ ) for grass, and/or weed pollen within 1 year prior to screening. Patients with an ear, nose, or throat infection or disease during the 2 weeks prior to or at the selection visit (e.g., sinusitis, purulent rhinorrhea, common cold) were excluded. Also excluded were patients with asthma, atopic dermatitis, or urticaria requiring nasal, oral, or topical corticosteroid treatment, or patients with an associated ENT disease (rhinitis medicamentosa, vasomotor rhinitis, obstructive nasal polyposis, significant chronic sinusitis). Patients with a history of drug or alcohol dependency within 1 year prior to randomization, or with a clinically significant disease or treatment known to affect driving ability were also excluded.

\section{SAR Symptoms and their Severity}

Patients should be willing to refrain from using antiallergic drugs during the winter period and the symptomatic period (approximately 7 days each). The T5SS diary card was used to assess SAR symptoms and their severity. Between training and test visits, patients had to assess the symptoms severity for the following 5 main rhinitis symptoms: sneezing, rhinorrhea, nasal pruritus, ocular pruritus, and nasal congestion, using a 4-point scale ranging from Absent (0), Mild (1), Moderate (2) to Severe (3). Patients were instructed to complete the daily record card at consistent times in the morning and evening with a 12 -hour interval. The mean a.m./p.m. reflective T5SS is defined as the average between both morning and evening reflective T5SS and was used as criteria for participation in the study. In summer (during the grass pollen season) patients must have a mean a.m./p.m. reflective T5SS $\geq 8$ throughout allergic period, i.e. between Visit 3 and Visit 4 (7 days). In winter, patients must have a mean a.m./p.m. reflective T5SS $\leq 3$ throughout the period between Visit 1 and Visit 2 (7 days) to make sure they did not suffer from rhinitis.

\section{Design}

Fig. (1) gives an overview of the study design. Patients started the study in winter, or in summer. They were trained (Visit 1) and then tested a week thereafter (Visit 2). The second test (Visit 4) was planned about six months later, and preceded by a second training day (Visit 3 ).
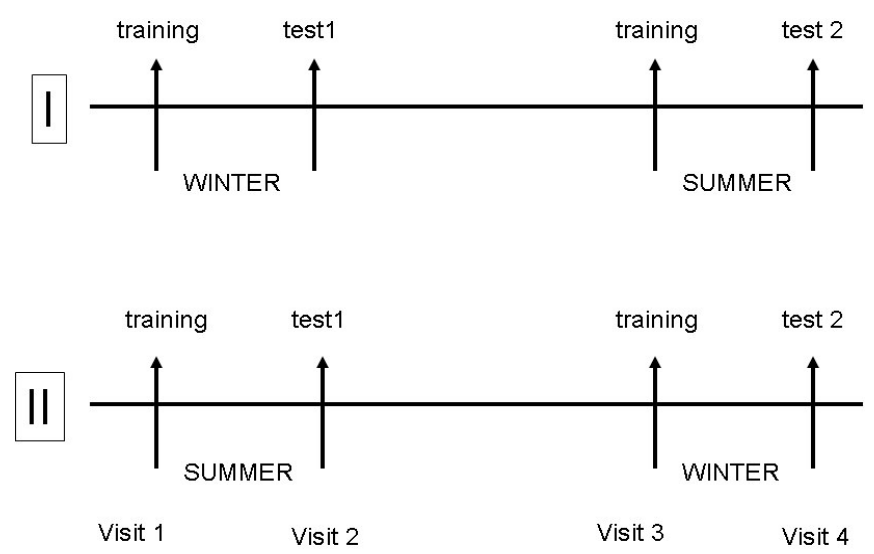

Fig. (1). Design of the study. Patients followed either sequence I or II. Training days and test days were separated by a drug free week.
At Visit 1 and Visit 3 (training days), patients were trained on the tests to obtain a stable baseline (i.e. dress rehearsal). The training day is a copy of the test day. In addition, they were also trained how to complete the T5SS diary card each day during the following week (T5SS scores were verified on the test days Visit 2 and Visit 4).

\section{Procedure of the Test Days (Visit 2 and Visit 4)}

Patients were instructed to travel by public transport to the Utrecht Institute for Pharmaceutical Sciences. After obtaining informed consent, patients had a breath alcohol test and a urine drug screening to test for the presence of amphetamines, barbiturates, cannabinoids, benzodiazepines, cocaine, and opiates. Any positive result would result in withdrawal of the patient from the study. Patients consumed a light, standard breakfast. Thereafter, the patient performed the first part of the word learning test (learning \& immediate recall). The patient was transported by an investigator to the origin of the highway circuit and performed the driving test. Upon completion, the patient was transported back to the Institute in Utrecht. Subjective assessments were completed during transportation. At the Institute, the patient performed the second part of the word learning test (delayed recall and recognition test) and the Continuous performance test. Thereafter, the patient traveled home by public transport.

\section{The On-The-Road Driving Test}

The on-the-road driving test was developed in the 1980s to establish a methodology to objectively examine driving impairment in a real life setting [16]. In the 100-km driving test, subjects drive an instrumented vehicle over a $50-\mathrm{km}$ highway track between the two Dutch cities of Utrecht and Arnhem. During the driving test, subjects are instructed to operate the instrumented vehicle with a constant speed and steady lateral position within the right (slower) traffic lane. Primary parameter is the Standard Deviation of Lateral Position (SDLP), i.e. the amount of weaving of the car (Figs. 1 and 2).

SDLP has been used in many driving studies. These studies were primarily set up to examine the effects of psychoactive drugs on driving ability. Dose-dependent increment of SDLP relative to placebo has been established for hypnotics, anxiolytics, antidepressants and antihistamines [13, 17-19]. As a historical reference for SDLP increments relative to placebo data with different dosages of alcohol is used [20]. SDLP increment with a blood alcohol concentration of $0.05 \%$, i.e. the most common legal limit for driving a car, is $2.4 \mathrm{~cm}$.

A camera, mounted on the roof of the car, continuously records the actual position of the car within the traffic lane, by tracking the relative distance of the car from the delineated stripe in the middle of the road. In the right front seat, a licensed driving instructor accompanies the subject. His main job is to guard safety during the driving test, and is equipped with a brake and clutch system to intervene with the subject's driving actions if necessary. If the subject or the driving instructor judges that it is unsafe to continue driving, the test is terminated before completion and the driving instructor transports the subject back to the Institute.

\section{Visual Analog Scales (VAS)}

After conclusion of the driving test, two types of retrospective self-assessment data (visual analog scales) will be 


\section{SCHEMATIC REPRESENTATION OF THE ON-THE-ROAD DRIVING TEST}

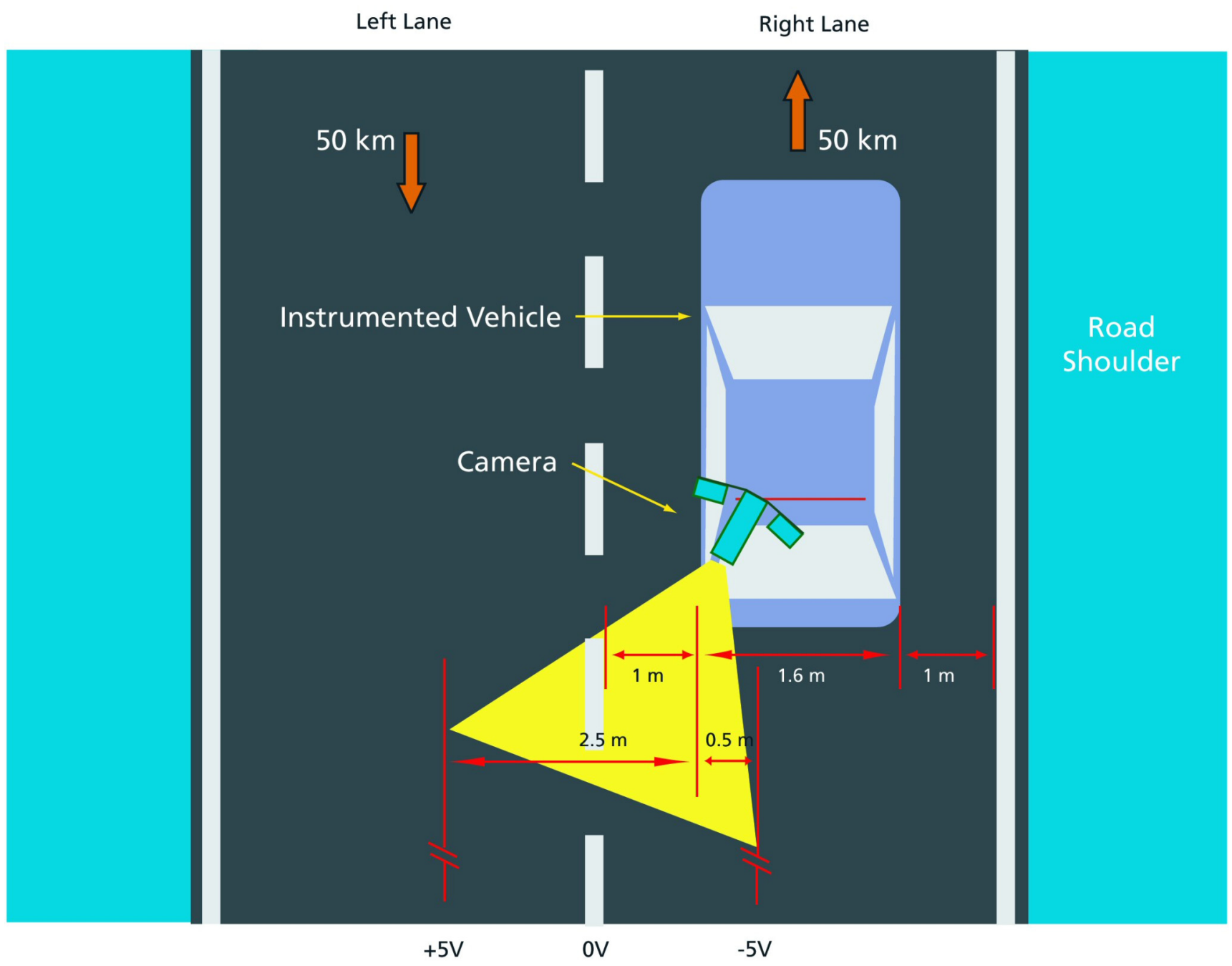

Fig. (2). Schematic representation of the driving test.

obtained from the patients in order to assess driving quality and mental effort during driving.

\section{Word Learning Test}

The word-learning test (Dutch language version) is a computerized and standardized test with high internal consistency and high test-retest reliability. The test consists of 12 parallel lists of 15 monosyllabic meaningful nouns (immediate and delayed recall), complemented with 15 distracter words in the recognition test. Each test day, different word lists were used. During immediate recall 15 words were presented five times on a computer display. After each presentation, subjects had to write down as many words they could remember. The highest trial score was a measure of immediate recall. After the driving test, delayed recall was recorded (approximately 2 hours after immediate recall). Finally, the original list along with 15 distracter words was presented. The subjects had to indicate by button-press whether a presented word was a member of the original list or not. Recognition was expressed in recognition time (ms) and recognition score (number of correct recognized words)

\section{Continuous Performance Test}

Subjects performed a 14-minutes continuous performance test. Continuously, letters are presented at the computer screen. A button should be pressed as soon as a letter appeared on the screen. However, no button should be pressed if the letter appeared to be an ' $X$ '. Mean reaction speed and the number of inhibition faults are the parameters of interest.

\section{Quality of Life Questionnaire}

Quality of life was measured using the Rhinitis Quality of Life Questionnaire [21]. Questions of 7 subscales concern sleep, non-rhinitis symptoms, practical problems, activities, emotional dysfunction, eye symptoms and nasal symptoms. The overall quality of life score is the average score of the subscale scores.

\section{Statistical Analysis}

Mean (SD) were computed for each variable. Analysis of Variance (ANOVA) for repeated measures was used to compare results from Visit 2 and Visit 4 (grass pollen season versus winter). A difference is regarded as significant if $p<$ 
0.05 (two-tailed). In case the distribution was not normal, nonparametric tests were used.

\section{RESULTS}

\section{Patients}

From the data base of the Utrecht Medical Center and by advertisement in local and nationwide newspapers, 70 subjects were recruited to participate in this study. Of these, 22 subjects were eligible to participate in the study. A flow chart of included and excluded participants is shown in Fig. (3).

48 participants were excluded. From the 22 participants that were included, 15 participants completed both winter driving tests and summer driving tests. Due to the mild summer of 2007, 5 participants did not experience any rhinitis complaints. Three subjects voluntary withdrew and 1 subject was lost to follow up. A total of 15 participants completed both winter and summer tests. Unfortunately, due to mild summer conditions, 3 subjects did not experience rhinitis complaints exceeding a T5SS score of 3. A fourth subject did, but her skin prick test revealed that she has no allergic rhinitis. Due to poor weather conditions only 5 participants met the T5SS score criteria ( $>8$ in summer); 6 other subjects had a T5SS score between 3 and 8. A statistical analysis based on 5 subjects is not reliable. We therefore chose to include all subjects with a T5SS score $>3$ in summer and T5SS score $<3$ in winter in the statistical analysis $(\mathrm{N}=11)$.
The 11 patients ( 8 women and 3 men) used in the analyses had a mean T5SS score of 6.8 in summer and 0.6 in winter. Mean (SD) age was 30.9 (11.2) and mean (SD) years of drivers license was 11.5 (11.0).

\section{Test Performance}

Table 1 summarizes the results of the driving test, VAS scales, memory test, and continuous performance test. Results from the word learning test (immediate and delayed recall and recognition score) and the number of inhibition faults of the CPT did not have a normal distribution and were analyzed non-parametrically. No significant practice or order effects were found.

\section{Driving}

For the SDLP measurements in winter (Visit 2) and summer (Visit 4), no significant difference was observed $\left(\mathrm{F}_{1,10}=0.308, \mathrm{p}<0.591\right)$. SDLP values in winter $(18.06 \mathrm{~cm})$ and summer $(18.45 \mathrm{~cm})$ are well within the range that is generally seen among regular drivers (an SDLP of $18-22 \mathrm{~cm}$ ). Analyses comparing untreated patients (Visit 3) and treated patients (Visit 4) also revealed no significant differences.

No significant difference between winter and summer was found for SD Speed $\left(\mathrm{F}_{1,10}=2.336, \mathrm{p}<0.157\right)$ and Mean Lateral Position $\left(\mathrm{F}_{1,10}=2.817, \mathrm{p}<0.124\right)$. Mean Speed differed significantly $\left(\mathrm{F}_{1,10}=5.916, \mathrm{p}<0.035\right)$ between winter

\section{CALCULATION AND MEANING OF THE "WEAVING INDEX" (SDLP)}

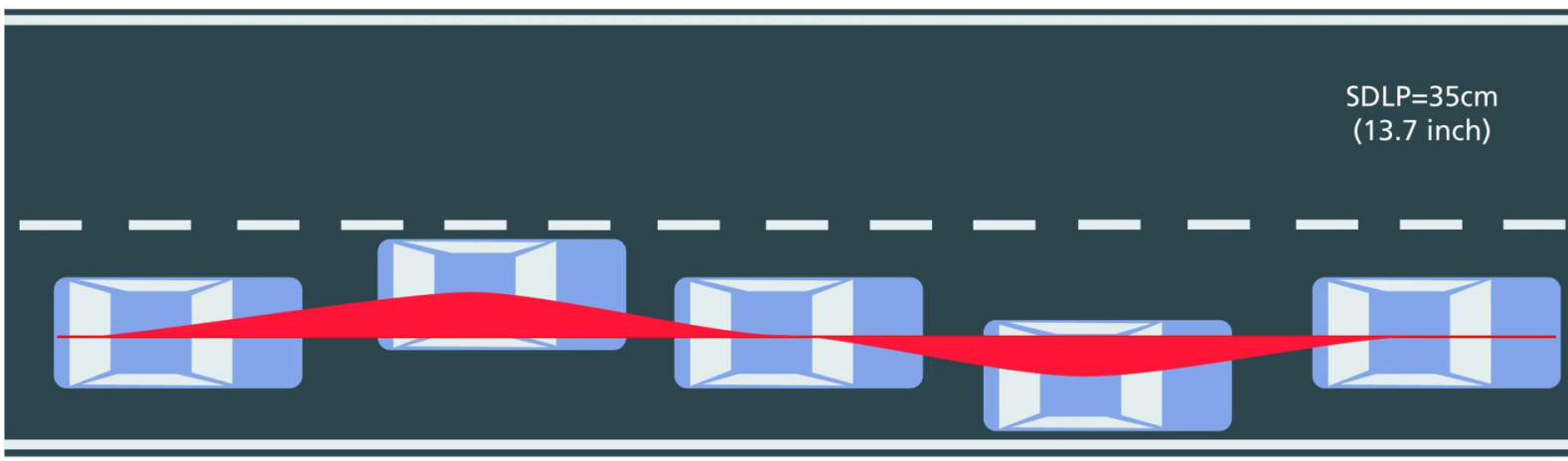
LANE
FURTHEST
LEFT
LANE
FURTHEST
RIGHT
POSITION OF
THE CAR
WITHIN THE LANE

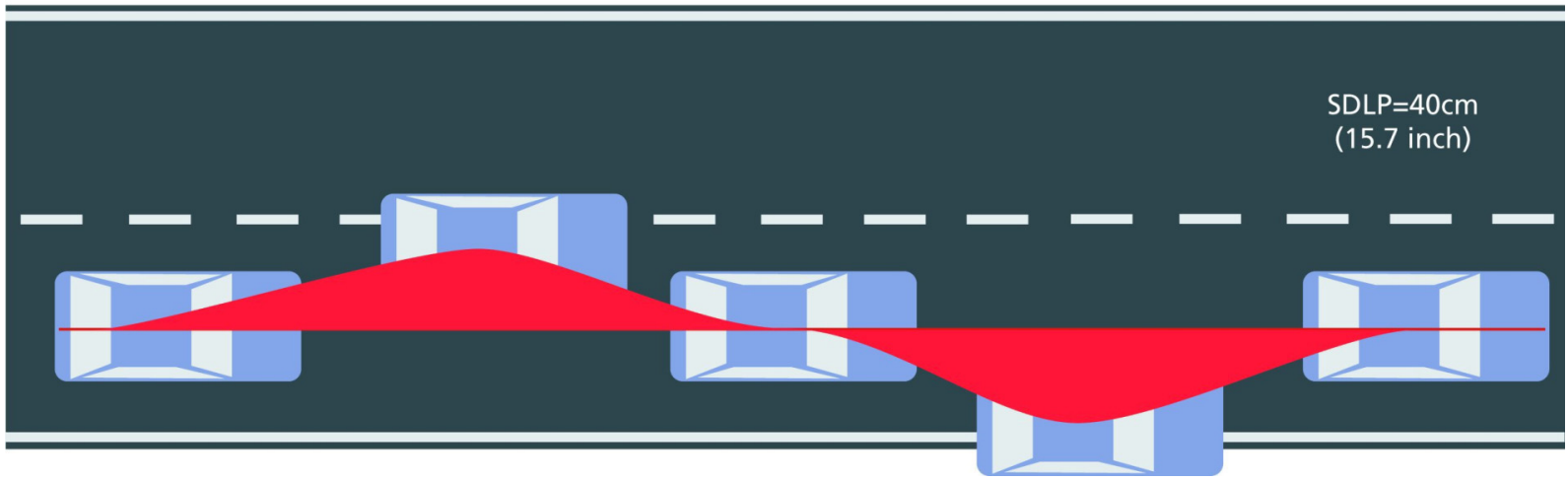

Fig. (3). Standard Deviation of Lateral Position (SDLP). 
$(94.5 \mathrm{~km} / \mathrm{h})$ and summer $(93.6 \mathrm{~km} / \mathrm{h})$, however, this difference has no relevance to driving safety.

Table 1. Results of the Tests During Grass Pollen Season (Summer) and Winter

\begin{tabular}{|c|c|c|c|}
\hline & \multirow{2}{*}{$\mathbf{N}$} & \multicolumn{2}{|c|}{ Mean (SD) } \\
\hline & & Winter & Summer \\
\hline \multicolumn{4}{|l|}{ Driving Test } \\
\hline $\operatorname{SDLP}(\mathrm{cm})$ & 11 & $18.06(2.8)$ & $18.45(4.1)$ \\
\hline Mean Lateral Position (cm) & 11 & $7.4(11.1)$ & $10.3(12.5)$ \\
\hline SD Speed $(\mathrm{km} / \mathrm{h})$ & 11 & $2.2(0.5)$ & $2.3(0.3)$ \\
\hline Mean Speed (km/h) & 11 & $94.5(1.2)$ & $93.6(0.9)$ \\
\hline \multicolumn{4}{|l|}{ VAS Scales } \\
\hline SDQ (mm) & 10 & $11.3(2.7)$ & $11.2(2.0)$ \\
\hline $\mathrm{ME}(\mathrm{mm})$ & 10 & $44.0(17.7)$ & $57.8(26.3)$ \\
\hline \multicolumn{4}{|l|}{ Word Learning Test } \\
\hline IR (\# words) & 11 & $13.3(1.6)$ & $13.3(2.1)$ \\
\hline DR (\# words) & 11 & $10.1(2.8)$ & $8.9(3.0)$ \\
\hline RecS (\# words) & 11 & $14.0(1.1)$ & $13.5(1.4)$ \\
\hline $\operatorname{RecT}(\mathrm{ms})$ & 11 & $733(163)$ & $715(142)$ \\
\hline \multicolumn{4}{|l|}{ Continuous Performance Test } \\
\hline RT (ms) & 11 & $299(28.0)$ & $297(34.4)$ \\
\hline Errors $(\%)$ & 11 & $13.2(7.9)$ & $11.9(4.4)$ \\
\hline
\end{tabular}

Mean scores and Standard Deviation (between brackets) are displayed. Differences are significant if $\mathrm{p}<0.05$. Abbreviations: SDLP $=$ Standard Deviation of Lateral Position, $\mathrm{SD}=$ Standard Deviation, SDQ $=$ Subjective Driving Quality, ME = Mental Effort, IR $=$ Immediate Recall, DR $=$ Delayed Recall, $\operatorname{RecS}=$ Recognition Score, RecT $=$ Recognition Time, $\mathrm{RT}=$ Reaction Time.

\section{VAS}

Consistent with the driving test data, subjective VAS scale measurement of perceived driving quality did not show a significant difference between Visit 2 and Visit. Also, there was no significant difference in mental effort to perform the driving between summer and winter.

\section{Word Learning Test}

No significant differences were observed between summer and winter for immediate recall, delayed word recall and recognition.

\section{Continuous Performance Test}

No significant differences were found between summer and winter for reactions speed and number of inhibition faults.

\section{Rhinitis Quality of Life Questionnaire}

Overall quality of life score during the grass pollen season was significantly lower when compared to the winter season $(p<0.0001)$. Significantly reduced quality of life during the grass pollen season was also profound on the subscales of sleep $(p<0.002)$, non-rhinitis symptoms $(p<0.0001)$, practical problems $(p<0.0001)$, activities $(p<0.0001)$, emotional dysfunction $(p<0.002)$, eye symptoms $(p<0.0001)$, and nasal symptoms $(p<0.0001)$. The correlation between the overall quality of life score and the T5SS scores during the grass pollen season showed a trend toward significance $(\mathrm{r}=$ $0.56, \mathrm{p}<0.069)$.

\section{Statistical Power}

Given the low number of subjects included in the statistical analyses, observed power was often low. Observed power ranged from 0.05 on the subjective driving quality scale to 0.59 for mean speed in the driving test.

\section{DISCUSSION}

In line with previous studies [10-12], we confirmed that patients who suffer from seasonal allergic rhinitis experience significantly reduced quality of life during the grass pollen season. Nevertheless, in our population of patients with moderate SAR complaints this did not result in significantly impaired driving performance, or memory and psychomotor impairment. Although this is the first study examining the complex ability of driving a car in real-life circumstances, laboratory studies examining more simple skills and abilities in patients with SAR did show significant impairment $[5,7$, 8]. A possible explanation for the differences in learning and memory effects may be that Vuurman and colleagues [7,8] tested primary school children, a group that may be more vulnerable to the sedative effects of SAR when compared to the adults who participated in our study. Marshall and Colon [5] reported significant effects on psychomotor tests of short duration. However, they reported no effects on a test of sustained attention. This is in line with the absence of effects found in our study on the 75-minute highway driving test, which can be viewed as a monotonous vigilance test, and the 14-minute continuous performance test.

Our study has several limitations that should be addressed. First of all, the number of subjects is low. Many patients were recruited, but as is evident from Fig. (4) most of them did not met the inclusion/exclusion criteria to participate in the study. Although the results are consistent in showing no significant effects of SAR on driving performance, they should be interpreted with some caution. Given this low number of patients that were included in the statistical analyses, the observed power was often low. Therefore, the results presented here should be interpreted with caution and future studies with a greater sample size should be performed to confirm our findings. The pollen season in this study was relatively mild. Therefore, 6 of 11 patients did experience only moderate SAR symptoms (T5SS scores between 3 and 8). It can be hypothesized that in patients who experience more severe SAR symptoms (T5SS score $>8$ ), the effects on driving and cognitive performance may be more pronounced. In this study, only 5 patients met these criteria and thus statistical analysis was not warranted. Another limitation is the fact that the study was not double blind. Given the set-up of this study, blinding was not possible. Finally, the mild intensity of the pollen season may have prevented significant effects on the tests. We recommend that a future study including more patients with more severe SAR symptoms should aim to have a double-blind design, performed during the grass pollen season only, comparing the effects of active treatment versus placebo. 


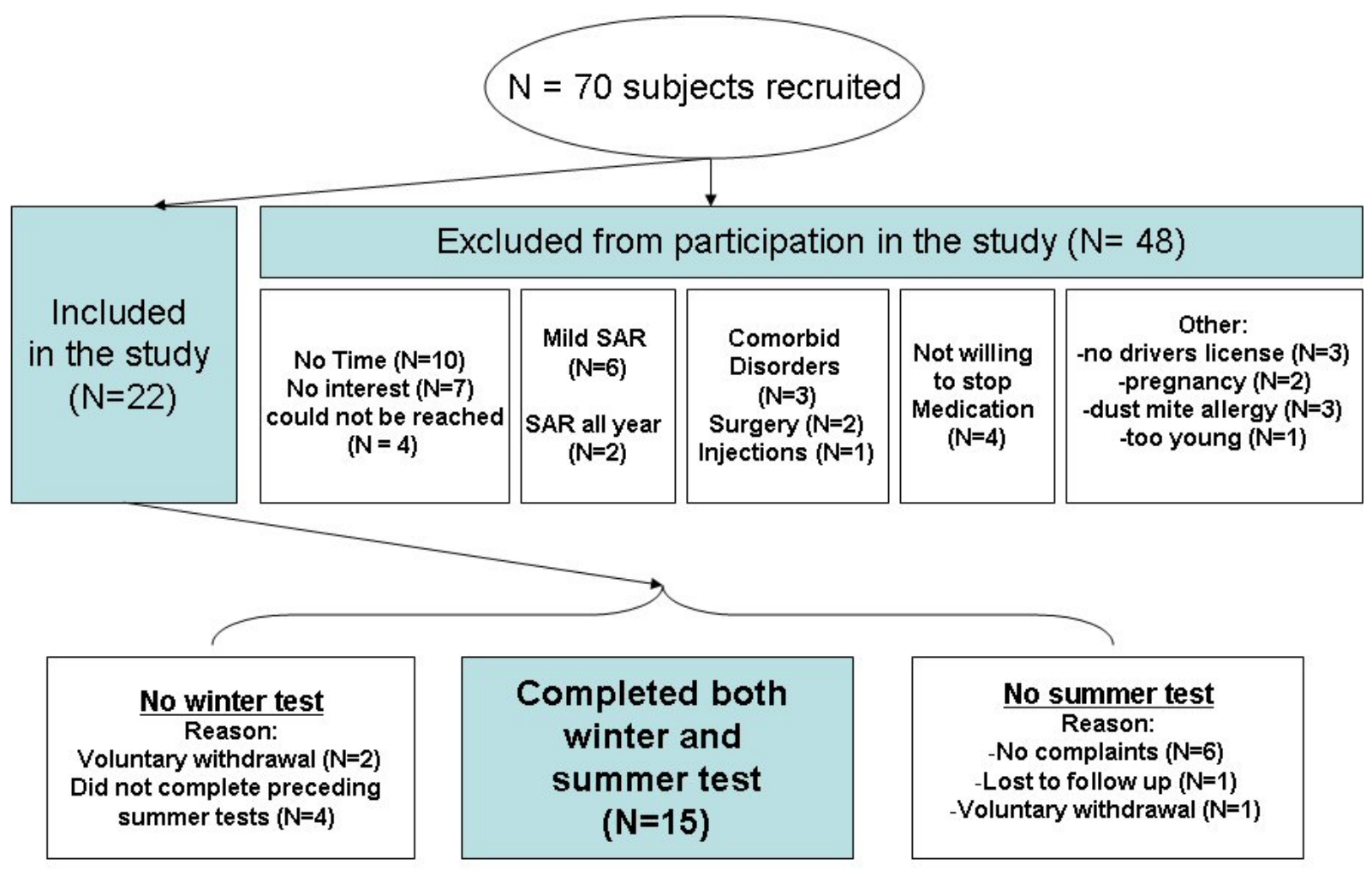

Fig. (4). Patient Flowchart.

Our results suggest that moderate SAR symptoms do impair quality of life during the grass pollen season but do not result in significantly impaired driving performance. However, given the small sample size and low observed power our results should be confirmed by future studies.

\section{ACKNOWLEDGEMENTS}

This study was sponsored by UCB. The authors have no conflicts of interest to declare.

\section{ABBREVIATIONS}

$\begin{array}{ll}\text { SAR } & =\text { Seasonal allergic rhinitis } \\ \text { T5SS } & =\text { Total 5-Symptoms Score } \\ \text { RAST } & =\text { Radioallergosorbent test } \\ \text { ENT } & =\text { Ear, nose and throat } \\ \text { SD } & =\text { Standard deviation } \\ \text { ANOVA } & =\text { Analysis of variance } \\ \text { SDLP } & =\text { Standard deviation of lateral position } \\ \text { VAS } & =\text { Visual analog scales }\end{array}$

\section{REFERENCES}

[1] Malone DC, Lawson KA, Smith DH, Arrighi HM, Battista C. A cost of illness study of allergic rhinitis in the United States. J Allergy Clin Immunol 1997; 99: 22-7.

[2] Storms WW. Treatment of allergic rhinitis: effects of allergic rhinitis and antihistamines on performance. Allergy Asthma Proc 1997; 18: $59-61$.

[3] Crystal-Peters J, Crown WH, Goetzel RZ, Schutt DC. The cost of productivity losses associated with allergic rhinitis. Am J Manag Care 2000; 6: 373-8.
[4] Kessler RC, Almeida DM, Berglund P, Stang P. Pollen and mold exposure impairs the work performance of employees with allergic rhinitis. Ann Allergy Asthma Immunol 2001; 87: 289-95.

[5] Marshall PS, Colon EA. Effects of allergy season on mood and cognitive function. Ann Allergy 1993; 71: 251-8.

[6] Blanc PD, Trupin L, Eisner M, et al. The work impact of asthma and rhinitis: findings from a population-based survey. J Clin Epidemiol 2001; 54: 610-8.

[7] Vuurman EPFM, Van Veggel LMA, Uiterwijk MMC, Leutner D, O'Hanlon JF. Seasonal allergic rhinitis and antihistamine effects on children's learning. Ann Allergy 1993; 71: 121-6.

[8] Vuurman EFPM, Van Veggel LMA, Sanders RL, Muntjewerff ND, O'Hanlon JF. Effects of semprex-D and diphenhydramine on learning in young adults with seasonal allergic rhinitis. Ann Allergy Asthma Immunol 1997; 76: 247-52.

[9] Cauci M, King MG, Saxarra H, Tulloch BJ, Husband AJ. A Minnesota Multiphasic Personality Inventory profile of women with allergic rhinitis. Psychosom Med 1993; 55: 533-40.

[10] Spaeth J, Klimek I, Mösges R. Sedation in allergic rhinitis is caused by the condition and not by the antihistamine treatment. Allergy 1996; 51: 893-906.

[11] Nolen TM. Sedative effects of antihistamines: safety, performance, learning and quality of life. Clin Ther 1997; 19: 39-55.

[12] Didier A, Doussau-Thuron S, Murris-Espin M. Comparative analysis of sedative effects of mequitazine and other antihistamine drugs: review of the literature. Cur Ther Res Clin Exp 2000; 61: 770-80.

[13] Verster JC, Volkerts ER. CME review. Antihistamines and driving ability: Evidence from on-the-road driving studies during normal traffic. Ann Allergy Asthma Immunol 2004, 92(3):294-303; quiz 303-5, 355. Erratum: 2004, 92(6): 675. Reply: 2005; 94: 409-10.

[14] Murray JJ, Nathan RA, Bronsky EA, Olufade AO, Chapman D, Kramer B. Comprehensive evaluation of cetirizine in the management of seasonal allergic rhinitis: impact on symptoms, quality of life, productivity, and activity impairment. Allergy Asthma Proc 2002; 23: 391-8.

[15] Meltzer EO, Casale TB, Nathan RA, Thompson AK. Once-daily fexofenadine $\mathrm{HCl}$ improves quality of life and reduces work and activity impairment in patients with seasonal allergic rhinitis. Ann Allergy Asthma Immunol 1999; 83: 311-7. 
[16] O'Hanlon JF, Haak TW, Blaauw GJ, Riemersma JBJ. Diazepam impairs lateral position control in highway driving. Science 1982; 217: 79-81.

[17] Verster JC, Veldhuijzen DS, Volkerts ER. Residual effects of sleep medication on driving ability. Sleep Med Rev 2004; 8: 309-25.

[18] Verster JC, Veldhuijzen DS, Volkerts ER. Is it safe to drive a car when treated with anxiolytics? Evidence from on-the-road driving studies during normal traffic. Curr Psychiatry Rev 2005; 1: 215-25.

[19] Ramaekers JG. Antidepressants and driver impairment: empirical evidence from a standard on-the-road test. J Clin Psychiatry 2003; 64: $20-9$.
[20] Louwerens JW, Gloerich ABM, De Vries G, Brookhuis KA, O'Hanlon JF. In: Noordzij PC, Roszbach R Eds, The relationship between drivers' blood alcohol concentration (BAC) and actual driving performance during high speed travel. Alcohol, Drugs and Traffic Safety. Amsterdam, Excerpta Medica. 1987; 183-92.

[21] Juniper EF, Guyatt GH, Andersson B, Ferrie PJ. Comparison of powder and aerosolized budesonide in perennial rhinitis: validation of the rhinitis quality of life questionnaire. Ann Allergy 1993; 70: 225-30.

Received: March 13, 2008

Revised: May 15, 2008

Accepted: June 4, 2008

(C) Mets et al.; Licensee Bentham Open.

This is an open access article distributed under the terms of the Creative Commons Attribution License (http://creativecommons.org/licenses/by/2.5/), which permits unrestrictive use, distribution, and reproduction in any medium, provided the original work is properly cited. 